\title{
Need satisfaction as a mediator between classroom goal structures and students' optimal educational experience
}

\author{
Ayşenur Alp ${ }^{\mathrm{a}, *}$, Aikaterini Michou ${ }^{\mathrm{b}}, \mathrm{M}$. Sencer Çorlu ${ }^{\mathrm{c}}$, Gamze Baray $^{\mathrm{b}}$ \\ a Middle East Technical University, Ankara, Turkey \\ b Bilkent University, Ankara, Turkey \\ ${ }^{\mathrm{c}}$ Bahçeșehir University, İstanbul, Turkey
}

\section{A R T I C L E I N F O}

\section{Keywords:}

Classroom goal structures

Need satisfaction

Educational satisfaction

Flow

Vitality

\begin{abstract}
A B S T R A C T
Goal-related messages in a classroom are associated with students' experiences and functioning in learning. However, little is known about need satisfaction as a mediator that translates the classroom messages into students' optimal educational experience. In the present studies, we investigated in a sample of 171 (in Study 1) and 255 (in Study 2) Turkish undergraduate students (60\% females; $M_{\text {age }}=19.79, S D=1.68$ and $45 \%$ females, $M_{\text {age }}=19.75, S D=1.67$ respectively), the relation of classroom goal structures to students' educational satisfaction (or vitality) and state flow through their experience of need satisfaction considering it as the psychological mediator. Path analysis with bootstrap showed that mastery goal structures (i.e., classroom environment focuses on learning and self-improvement) were positively related to need satisfaction while performance goal structures (i.e., classroom environment focuses on normative success) were either negatively related (Study 1) or unrelated (Study 2) to need satisfaction. Path analysis with bootstrap also showed that mastery goal structures were related to vitality, educational satisfaction and flow in class-related tasks through need satisfaction. Understanding need satisfaction as a mediator of classroom goal structures and optimal educational experience help teachers to reconsider their goal-related messages in the classroom.
\end{abstract}

\section{Introduction}

The motivational environment that teachers create in the classroom is related to students' psychological experience and functioning in educational settings. Studies conducted in the framework of Achievement Goal Theory (AGT; Elliot \& Dweck, 2005) have shown that when students perceive that their teachers are focusing on learning and orienting them towards self-improvement (i.e., mastery goal structures; MGSs) compared to competition and normative success (i.e., performance goal structures; PGSs), they report adaptive patterns of behavior, affect and cognition (Kaplan \& Midgley, 1999; Meece, Anderman, \& Anderman, 2006; Skaalvik \& Skaalvik, 2013). However, little is known about the need-related psychological experience that translates the learning-oriented classroom messages into adaptive patterns of behavior, affect, and cognition.

Up to now, mostly, competence-based motivation (such as students' achievement goals or self-efficacy) has been considered as a mediator between classroom goal structures and educational outcomes (Fast et al., 2010; Michou, Mouratidis, Lens, \& Vansteenkiste, 2013; Shim, Cho, \& Wang, 2013). In the present study, we assumed that students' adaptive functioning in MGSs are also related to students' satisfaction of their psychological needs as they have been defined by Self-Determination Theory (SDT; Deci \& Ryan, 2000). On the one hand, MGSs respect students' own pace in developing their competence and empowers learning instead of competition (Meece, 1991; Patrick \& Ryan, 2005). Consequently, it can help students to satisfy their own needs, such as being agents of their own actions (satisfaction of need for autonomy), feeling competent in classroom activities (satisfaction of need for competence) and relating their actions to those of others (satisfaction of need for relatedness). On the other hand, when students perceive their teachers focusing on performance and normative success (i.e., PGSs), they report less adaptive patterns of behavior, affect and cognition (Kaplan \& Midgley, 1999; Meece et al., 2006; Skaalvik \& Skaalvik, 2013). Probably, this is because students feel forced to follow and overcome others' pace in learning (frustration of need for autonomy), prove their ability (frustration of need for competence) and be opponents to their classmates (frustration of need for relatedness).

In an experimental laboratory study, Standage, Duda, and Pensgaard (2005) found that a mastery oriented environment during a co-ordination dance task was positively related to participants' need

\footnotetext{
* Corresponding author.

E-mail addresses: aysenur.alp@metu.edu.tr (A. Alp), aliki.michou@bilkent.edu.tr (A. Michou), mehmetsencer.corlu@rc.bau.edu.tr (M.S. Çorlu), gbaray@bilkent.edu.tr (G. Baray).
} 
satisfaction and subjective well-being, while a performance oriented environment was negatively related to need satisfaction and well-being. However, this relation has not been investigated in educational settings. Moreover, even though there is evidence for an interaction of MGSs and PGSs in the prediction of educational outcomes (see Skaalvik \& Federici, 2016), it has not been investigated whether perceived MGSs are positively related to need satisfaction independently of perceived PGSs or whether the two types of classroom goal structures interact in the prediction of need satisfaction. As MGSs conceptually seem compatible with need satisfaction, when such structures are perceived high by students in a classroom, they may attenuate the negative relationship of perceived performance goal structures to need satisfaction. If so, the interaction between MGSs and PGSs may also have an indirect effect on students' functioning and educational experience.

The first aim of the present study is to examine if students' need satisfaction is one of the mediators that translates the perceived classroom goal-related messages to educational experiences and therefore, whether the need satisfaction mediates the relation between students' perceived classroom goal structures and their educational satisfaction, vitality and state flow as indicators of their optimal educational experience. The second aim of the present study is to investigate to what extent the two types of the classroom goal-related messages, mastery and performance, are independently related to need satisfaction, and whether or not high perception of one type moderates the relation of the other type to need satisfaction. We believe that understanding need satisfaction as the mediator of classroom goal-related messages and optimal educational experiences help to reconsider the value of MGSs or PGSs.

\subsection{Classroom goal structures}

Classroom goal structures can be defined as teachers' goal-related messages that are communicated to students during classroom activities (Ames, 1992; Murayama \& Elliot, 2009; Urdan, 2004a). For example, if a teacher emphasizes the demonstration of high competence proved by distinguished achievement, students tend to perceive that they should study to outperform others. Alternatively, if a teacher stresses understanding, learning, and self-improvement, students perceive that they need to study in order to learn and develop their competence in the given field. These two different examples correspond to PGSs and MGSs, respectively. MGSs indicate that the classroom environment is oriented towards understanding and learning, while PGSs mean that the classroom climate is oriented towards a normative success (Anderman \& Midgley, 1997; Covington, 2000; Midgley et al., 1998; Murayama \& Elliot, 2009; Nicholls, 1984).

Previous research showed that MGSs have adaptive while PGSs have maladaptive outcomes. Specifically, MGSs are positively associated with intrinsic motivation and academic self-concept (Murayama \& Elliot, 2009), self-efficacy (Roeser, Midgley, \& Urdan, 1996), use of effective learning strategies such as self-regulated learning (Wolters, 2004), deep level learning strategies (Michou et al., 2013; Miki \& Yamauchi, 2005) and the experience of flow (Harwood, Keegan, Smith, \& Raine, 2015). PGSs, on the other hand, are negatively related to intrinsic motivation (Meece et al., 2006), positively associated with surface level learning (Miki \& Yamauchi, 2005), and self-handicapping strategies (Urdan \& Midgley, 2001) or unrelated to learning strategies and achievement (Matos, Lens, Vansteenkiste, \& Mouratidis, 2017). Few studies have also investigated the effects of multiple goal structures (i.e., focus on both MGSs and PGSs) on optimal educational experience. For instance, Linnenbrink (2005) found in an experimental study that the multiple goal structures condition has a positive and a significant effect on help seeking and achievement in elementary school students. Peng, Cherng, and Chen (2013), however, found that the multiple goal structures condition did not differ from the MGSs condition regarding their positive effects on creativity. Peng et al.'s (2013) finding indicates that the MGSs are enough to enhance high school students' creativity.
Since MGSs and PGSs predict different optimal educational experiences, they might also create different psychological experiences that mediate the relationship between students' perception about classroom goal structures and educational outcomes. The mediated psychological experiences can include, among others, the degree of students' psychological need satisfaction as it has been described by SDT (Deci \& Ryan, 2000). By considering need satisfaction as the psychological experience that link classroom goals structures to outcomes, we deemed important to investigate also whether the need satisfaction is higher when multiple goal structures are perceived in a classroom compared to when one type of goal structures is perceived high and the other low.

\subsection{Need satisfaction}

According to SDT, there are three basic psychological needs: the need for autonomy, the need for competence, and the need for relatedness (Ryan \& Deci, 2000). The need for autonomy refers to a sense of volition and agency. The need for competence corresponds to a sense of effectiveness, while the need for relatedness refers to a sense of belongingness and connectedness to others. When these needs are satisfied, personal growth and optimal functioning are achieved, whereas when the basic psychological needs are unmet, people experience illbeing (Ryan \& Deci, 2000).

Research has shown that need satisfaction in educational settings enhances intrinsic motivation in the classroom (Niemiec \& Ryan, 2009) and predicts students' general subjective well-being (Sheldon \& Elliot, 1999), positive affect, school satisfaction (Tian, Chen, \& Huebner, 2014), academic satisfaction and personal well-being (Mavor, Platow, \& Bizumic, 2017, p.187), and school engagement (Skinner, Furrer, Marchand, \& Kindermann, 2008). Similarly, in other settings, need satisfaction is related to flow experience (Schüler \& Brandstätter, 2013; Schüler, Brandstätter, \& Sheldon, 2013) and well-being (Gagne, Ryan, \& Bergman, 2003; Reinboth \& Duda, 2006) in sport, identity exploration during identity formation (Madjar \& Cohen-Malayev, 2013), and pro-environmental behavior (Pelletier, 2002).

Previous research, thus, suggest that, optimal functioning and subjective-well-being are strongly associated with need satisfaction. Moreover, previous research that aimed to unveil the environmental conditions that facilitate individuals' need satisfaction have showed that when teachers are need-supportive, (e.g., give choices to and share the decision-making process with students) instead of being controlling (e.g., force students to act in particular ways), students report higher levels of need satisfaction (Niemiec \& Ryan, 2009; Reeve, 2009). More specifically, research findings have indicated a mediating role of need satisfaction between need-supportive environment and positive outcomes. For example, it has been shown that need satisfaction mediates the relationship between perceptions of coach autonomy support and well-being (Adie, Duda, \& Ntoumanis, 2012), secondary school students' perceived autonomy support and autonomous motivation (Haerens, Aelterman, Vansteenkiste, Soenens, \& Van Petegem, 2015), and adolescents' perceived structure (i.e. perception of clear expectations and scaffolding provided by the teacher) and learning strategies and affect (Mouratidis, Vansteenkiste, Michou, \& Lens, 2013; Reeve, 2006).

Thus, a considerable amount of research suggests that need satisfaction can be considered as a necessary psychological experience which mediates the relationship between need-supportive environment and individuals' well-being. The question is, therefore, to what extent need satisfaction can be also considered a necessary mediator between classroom goal structures and students' optimal educational experiences. Research in the sport context, for instance, has shown that perceived mastery climate was positively related to hip-hop dancers' need satisfaction (Quested \& Duda, 2009). This is because mastery-focused climate fosters feelings of belongingness, feelings of efficacy (Harwood et al., 2015) and feelings of agency (Standage, Duda, \& Ntoumanis, 2003). However, performance-focused climate seems either to be 
negatively related to the fulfillment of need for relatedness (Harwood et al., 2015; Quested \& Duda, 2009) and autonomy (Harwood et al., 2015) or to not be related to need satisfaction (Quested \& Duda, 2009; Standage et al., 2003). Reinboth and Duda (2006) found also task involving coaching climate (a type of MGSs where emphasis is given on self-improvement, effort and shared contribution to the team's progress) to predict positively need satisfaction at the end of the training period, while ego involving coaching climate (a type of PGSs environment) did not predict negatively competence and autonomy satisfaction.

Research in sport settings provides evidence for the positive relation between MGSs and need satisfaction. Moreover, research in both sport and educational settings provides evidence for the positive relation between need satisfaction and desired optimal educational experiences. However, it remains unexplored to what extent MGSs or PGSs are related to need satisfaction, and through it to students' state flow and educational satisfaction or vitality, which are some of the indicators of optimal educational experience. We deem educational satisfaction, vitality and state flow as aspects of optimal educational experience because they have all been considered as indicators of subjective wellbeing (Demirbatir, 2015; Diener, 1984; Haq \& Zia, 2013; Michalos, 2012; Ryan \& Deci, 2001) and optimal educational experience (Csikszentmihalyi, 1990, 1997; Jackson \& Marsh, 1996).

\subsection{Present research}

In the present research, we examined, in two studies, the relationship between students' perceived classroom goal structures, namely mastery and performance, need satisfaction, and optimal educational experience as it is expressed by state flow and educational satisfaction or vitality. We deemed important to investigate this relationship in two similar studies so as to address in Study 2 methodological weaknesses of Study 1 explained below.

The current studies extend previous research in some important ways. First, these studies investigated the relation of perceived achievement goal structures to need satisfaction in educational settings instead of sports context. Based on previous research in sport settings and taking into consideration that normative success is a less inherent characteristic of learning and education as it is of sports, we anticipated that perceived MGSs would be positively and perceived PGSs would be negatively related to students' need satisfaction (Hypothesis 1).

Second, the present studies investigated to what extent one type of classroom goal structure moderates the relationship between another type of classroom goal structures and need satisfaction. Linnenbrink (2005) found that the multiple goal structures have positive effects only on two out of nine educational outcomes. Similarly, Peng et al. (2013) found that the multiple goal structures do not differ from the MGSs regarding their positive effects on creativity, whereas Skaalvik and Federici (2016) found that performance goal structures moderate significantly the relationship between a MGSs and students' personal goal orientations. Based on these findings, we hypothesized that MGSs will attenuate any negative relationship between performance goals structures and need satisfaction and vice versa (Hypothesis 2).

Finally, the study examined the explanatory role of need satisfaction as a mediator between classroom goal structures and optimal educational experience. In doing so, we chose state flow and educational satisfaction or vitality as indicators of students' optimal educational experience because they have been considered as aspects of students' subjective well-being (Csikszentmihalyi, 1990, 1997; Diener, 1984; Jackson \& Marsh, 1996; Ryan \& Deci, 2001). Relying on the findings about the mediating role of need satisfaction between need-supportive environment and educational outcomes, we assumed that MGSs, a classroom environment compatible to psychological needs, would positively predict educational satisfaction or vitality and state flow through need satisfaction, whereas PGSs, a classroom environment that emphasizes competition, would negatively predict educational satisfaction or vitality and state flow through need satisfaction as a psychological mediator (Hypothesis 3).

\section{Study 1}

In Study 1, it was investigated the relationship of perceived MGSs and PGSs at a specific university course with students' need satisfaction and need frustration in their university studies in general as well as with students' educational satisfaction and flow experience during in-class activities or homework.

\subsection{Method}

\subsubsection{Participants and procedure}

Participants were 171 (60\% females, 18 students did not report their gender; $\mathrm{M}_{\text {age }}=19.79, S D=1.68,14$ students did not report their age) Turkish university students from a private non-profit university in an urban area of Turkey. Eighty-six students came from social sciences and 82 students came from engineering and sciences ( 3 students did not report their department).

After getting ethical approval from the university's Ethical Committee, a research assistant administered a survey according to human subjects' principles. The survey lasted about $20 \mathrm{~min}$. Before students completed the survey, they were informed about the purpose of the study and they were ensured that their participation was anonymous and voluntary. Participants were also informed that they could withdraw from the study at any time. Upon signing the consent form, participants reported their need satisfaction and need frustration in their university studies in general, the classroom goal structures of the specific course during which the data were collected (i.e., Algorithms and Programming I, Introduction to Psychology and Social and Political Philosophy I), their educational satisfaction with their university studies, and the flow experience during in-class activities or homework. The courses for which the students reported the classroom goal structures were obligatory for some of the students but elective for some others. All the instruments were translated to Turkish and they were adjusted according to the procedures proposed by Hambleton (1994). Each item in the questionnaires was assessed in a five-point, Likert-type scale ranging from 1 to 5 , where 1 represented strong disagreement, and 5 represented strong agreement with the given statement.

\subsubsection{Measures}

2.1.2.1. Background variables. Students were asked to indicate their gender, age and department. The departments were categorized according to the classification used in Turkish high schools and university exams into social sciences and engineering and sciences departments. Therefore, psychology, political science, management, law, international relations, and economics departments were classified as social science departments; industrial engineering, electrical electronics engineering, computer engineering, physics and molecular biology departments were classified as engineering and science departments.

2.1.2.2. Classroom goal structures. Students' perception about classroom goal structures in a specific university class was assessed with 10 items from the Patterns of Adaptive Learning Scale (PALS; Midgley et al., 2000) and Urdan's (2004b) scale. Four items assessed performanceapproach goal structures (e.g. in our class, getting good grades is the main goal) while six items assessed MGSs (e.g., in our class, it's important to understand the work, not just memorize it). A Confirmatory Factor Analysis (CFA) with two latent factors (one for PGSs and one for MGSs) yielded an adequate fit (see Table 3).

2.1.2.3. Need satisfaction. Students' need satisfaction and frustration were assessed by the Balanced Measure of Psychological Needs (BMPN; Sheldon \& Hilpert, 2012). Nine items assessed need satisfaction (3 items for need for autonomy; e.g., I was free to do things my own way, 
$\alpha=0.57 ; 3$ items for need for competency; e.g., I was successfully completing difficult tasks, $\alpha=0.82$; and 3 items for need for relatedness; e.g., I felt close and connected with other people, $\alpha=0.70$ ). Accordingly, nine statements measured need frustration (3 items for need for autonomy; e.g., There were people telling me what I had to do, $\alpha=0.36 ; 3$ items for need for competence; e.g., I did something that made me feel incompetent, $\alpha=0.47$; and 3 items for need for relatedness; e.g., I had disagreements or conflicts with people, $\alpha=0.47)$. A CFA for a model where each set of the three items loaded on the respective latent factor, loaded on two higher-order latent factors, termed need satisfaction and need frustration did not yield an acceptable fit: $S-B \chi^{2}(131, N=154)=188.67, p<.01$, CFI $=0.876$, SRMR $=0.09$, RMSEA $=0.054$ (90\%-CI: 0.035-0.070). Given the low internal consistency of the need frustration subscales, we tested a CFA model in which the three sets of items of the need satisfaction subscales loaded on the respective latent factor loaded on a higher-order latent factor, termed need satisfaction. The fit of the model was good (see Table 3) and therefore a composite score of need satisfaction for each student was created by aggregating the nine items. The nine items of the need frustration subscales where excluded from the analysis.

2.1.2.4. Educational satisfaction. Five items from the Satisfaction with Life Scale (Diener, Emmons, Larsen, \& Griffin, 1985) were adapted to educational life and assessed students' educational satisfaction (e.g., In most ways my educational life is close to my ideal). A CFA with the five items loading on a latent factor yielded a good fit (see Table 3 ).

2.1.2.5. State flow experience. Nine items from the Flow State Scale-2 (Jackson \& Eklund, 2002) were used to assess students' flow experience during in-class activities or homework. Each of the nine items corresponded to one of the nine dimensions of flow (i.e., challengeskill balance, action-awareness merging, clear goals, unambiguous feedback, concentration on task, time transformation and autotelic experience; e.g., Time flows while working on the task). A CFA with the nine items loading on a latent factor yielded an adequate fit (see Table 3).

\subsubsection{Plan of analysis}

We performed a CFA to verify the factor structure of all scales (see Measures section and Table 3). For preliminary analyses, we examined the descriptive statistics of the measured variables and the bivariate correlations among them by using SPSS 18 . We also examined differences between disciplines and genders through MANOVA (see Table 1).

The main analyses involved path analysis with bootstrap using $\mathrm{R}$ programming software (package Lavaan) to investigate the mediating role of need satisfaction in the relationship of perceived classroom goal structures to educational satisfaction and state flow. As moderating effects of classroom goal structures on need satisfaction were hypothesized, the interaction term of MGSs by PGSs as well as MGSs and PGSs were included in the exogenous variables of the model. Perceived MGSs and PGSs, educational satisfaction and state flow were represented by the mean score of the measured variable and then centered around the mean. The interaction term of MGSs by PGSs was produced by multiplying the centered MGSs by the centered PGSs. Need satisfaction was defined by the mean of autonomy, competence and relatedness satisfaction and then centered around the mean.

The chi-square $\left(S-B \chi^{2}\right)$, the root mean square error of approximation (RMSEA), the standardized root mean square residual (SRMR) and the comparative fit index (CFI) were used as indicators of model fit. A non-significant chi-square reflects a good model fit. SRMR at or $<0.05$ reflects good fit (Hu \& Bentler, 1995) while, $0.05<$ SRMR $<0.08$ reflects adequate fit. RMSEA at or $<0.05$ and $0.05<$ RMSEA $<0.08$ represents a good and adequate fit respectively. Finally, $0.90<\mathrm{CFI}<0.95$ and $\mathrm{CFI}>0.95$ reflects adequate and good model fit respectively (Hu \& Bentler, 1999; Kline, 2011). The tested model was estimated by both Maximum Likelihood with robust standard errors and scaled chi-square (MLM) and Bootstrap with 10,000 replications and $95 \%$ confidence interval $(C D)$. Confidence intervals which do not include zero (0.00) indicate that the tested relationship is $95 \%$ reliable. In the results, we first report the beta coefficients of MLM and then confidence intervals of Bootstrap.

\subsection{Results}

\subsubsection{Preliminary analysis}

Descriptive statistics and bivariate correlations among the measured and background variables are presented in Table 2 .

MANOVA did not yield significant gender differences but it showed significant differences between social sciences and engineering - sciences (Wilk's $\Lambda=0.861, F[5,139]=4.49, p<.01$, multivariate $\eta^{2}=0.14$ ). Taking into consideration this difference as well as that age was significantly correlated with perceived MGSs and state flow, discipline and age were included as covariates in the subsequent analyses.

\subsubsection{Main analysis}

A path analysis was conducted to test our hypotheses. Inspection of Fig. 1 shows that all the hypothesized paths were significant and fit indices were good: $\mathrm{S}-\mathrm{B} \chi^{2}(6, N=133)=2.45, p^{<} .01 . \mathrm{CFI}=1.000$, SRMR $=0.016$, RMSEA $=0.000(90 \%-C I: 0.000-0.057)^{1}$. However, reports of only 133 (out of 171) students were included in the analysis due to missing values. As Fig. 1 shows, perceived MGSs were positively related to need satisfaction (MLM: $\beta=0.35, p<.01$; Bootstrap: $95 \%$ CI: $0.10-0.38$ ) and perceived PGSs were negatively related to need satisfaction (MLM: $\quad \beta=-0.30, \quad p<.01$; Bootstrap: $95 \%-C I$ : $-0.27-0.07$ ), confirming our Hypothesis 1 .

It is worthy to note that perceived MGSs and need satisfaction were presented uncorrelated in the zero-order correlations while in the path model, when controlling for perceived PGSs, their relation appeared positive and significant. This result further supports an interaction between perceived MGSs and PGSs in the prediction of need satisfaction. Indeed, the interaction between MGSs and PGSs was also positively related to need satisfaction (MLM: $\beta=0.27, p<.05$; Bootstrap: $95 \%$ CI: 0.04-0.25). Inspection of Fig. 2 shows that students' need satisfaction was lower when PGSs were high and MGSs low compared to when both PGSs and MGSs were high.

Both educational satisfaction and state flow were positively related to need satisfaction (MLM: $\beta=0.42, p<.01$; Bootstrap: $95 \%-C I$ : 0.43-0.93 and MLM: $\beta=0.44, p<.01$; Bootstrap: $95 \%-C I$ : $0.30-0.62$ respectively). A test of indirect effects showed that need satisfaction was mediated the relationship between perceived classroom goal structures and educational satisfaction and state flow confirming Hypothesis 3. More specifically, need satisfaction mediated the relationship between MGSs and educational satisfaction (MLM: $B=0.16$, $S E=0.06, z=2.63, \beta=0.15, p<.01$; Bootstrap: 95\%-CI: 0.05-0.27), MGSs and state flow (MLM: $B=0.11, S E=0.04, z=2.62, \beta=0.15$, $p<.01$; Bootstrap: 95\%-CI: 0.04-0.19), PGSs and educational satisfaction (MLM: $B=-0.11, S E=0.05, \quad z=-2.34, \quad \beta=-0.12$, $p<.05$; Bootstrap: 95\%-CI: $-0.19--0.03$ ), as well as PGSs and state flow (MLM: $B=-0.08, S E=0.03, z=-2.56, \beta=-0.13, p<.01$; Bootstrap: $95 \%-C I$ : $-0.13--0.02)^{1}$. We also checked the mediation of a moderator effect (Fairchild \& MacKinnon, 2009; Frazier, Tix, \& Barron, 2004) by examining the indirect effect of the interaction term to educational satisfaction and state flow through need satisfaction. Need satisfaction mediated the relationship between the interaction of MGSs and PGSs and educational satisfaction (MLM: $B=0.10$, $S E=0.05, z=2.13, \beta=0.11, p<.05$; Bootstrap: 95\%-CI: 0.02-0.18) as well as the relationship between the interaction of MGSs and PGSs

\footnotetext{
${ }^{1}$ We also run a model with direct paths from classroom goal structures to educational satisfaction and flow but none of the direct paths for this partial mediation model were significant.
} 
Table 1

CFA results and Cronbach alphas of the measured variables in Study 1.

\begin{tabular}{|c|c|c|c|c|c|c|c|c|}
\hline Variables & $\alpha$ & $\chi^{2}$ & $N$ & $d f$ & CFI & RMSEA & SRMR & $90 \%-C I$ \\
\hline Classroom goal structures & $\begin{array}{l}\alpha_{\mathrm{M}}=0.87 \\
\alpha_{\mathrm{P}}=0.84\end{array}$ & 66.34 & 146 & 34 & 0.926 & 0.079 & 0.017 & $0.049-0.107$ \\
\hline Need satisfaction & $\alpha=0.71$ & 31.73 & 165 & 25 & 0.975 & 0.041 & 0.060 & $0.000-0.078$ \\
\hline Educational satisfaction & $\alpha=0.86$ & 2.99 & 163 & 5 & 1.000 & 0.000 & 0.017 & $0.000-0.082$ \\
\hline State flow & $\alpha=0.72$ & 41.34 & 168 & 27 & 0.935 & 0.071 & 0.063 & $0.039-0.101$ \\
\hline
\end{tabular}

Note. $\alpha_{\mathrm{M}}=$ Cronbach alpha for MGSs, $\alpha_{\mathrm{P}}=$ Cronbach alpha for PGSs.

Table 2

Means, standard deviations and bivariate correlations of the measured variables in Study 1.

\begin{tabular}{|c|c|c|c|c|c|c|c|c|}
\hline Variables & 1 & 2 & 3 & 4 & 5 & 6 & 7 & 8 \\
\hline \multicolumn{9}{|l|}{ Background variables } \\
\hline 1. Age & 1 & & & & & & & \\
\hline 2. Gender & 0.01 & 1 & & & & & & \\
\hline 3. Discipline & $-0.27^{* *}$ & 0.10 & 1 & & & & & \\
\hline \multicolumn{9}{|l|}{ Independent variables } \\
\hline 4. MGSs & $-0.24 * *$ & 0.05 & 0.08 & 1 & & & & \\
\hline 5. PGSs & -0.11 & 0.06 & $0.34 * *$ & $0.36^{* *}$ & 1 & & & \\
\hline \multicolumn{9}{|l|}{ Dependent variables } \\
\hline 6. Need satisfaction & -0.13 & $0.18^{*}$ & -0.04 & 0.10 & $-0.21 * *$ & 1 & & \\
\hline 7. Educational satisfaction & -0.15 & -0.07 & -0.04 & 0.07 & -0.10 & $0.42^{* *}$ & 1 & \\
\hline 8. Flow & $-0.17^{*}$ & -0.03 & 0.05 & -0.01 & -0.08 & $0.45^{* *}$ & $0.49 * *$ & 1 \\
\hline$M$ & 19.97 & 0.40 & 0.49 & 3.95 & 3.09 & 3.59 & 3.15 & 3.29 \\
\hline$S D$ & 1.66 & 0.49 & 0.50 & 0.81 & 0.99 & 0.56 & 0.89 & 0.59 \\
\hline
\end{tabular}

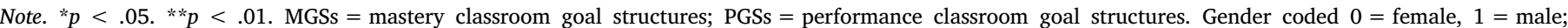
Discipline coded $0=$ social sciences, $1=$ engineering and sciences.

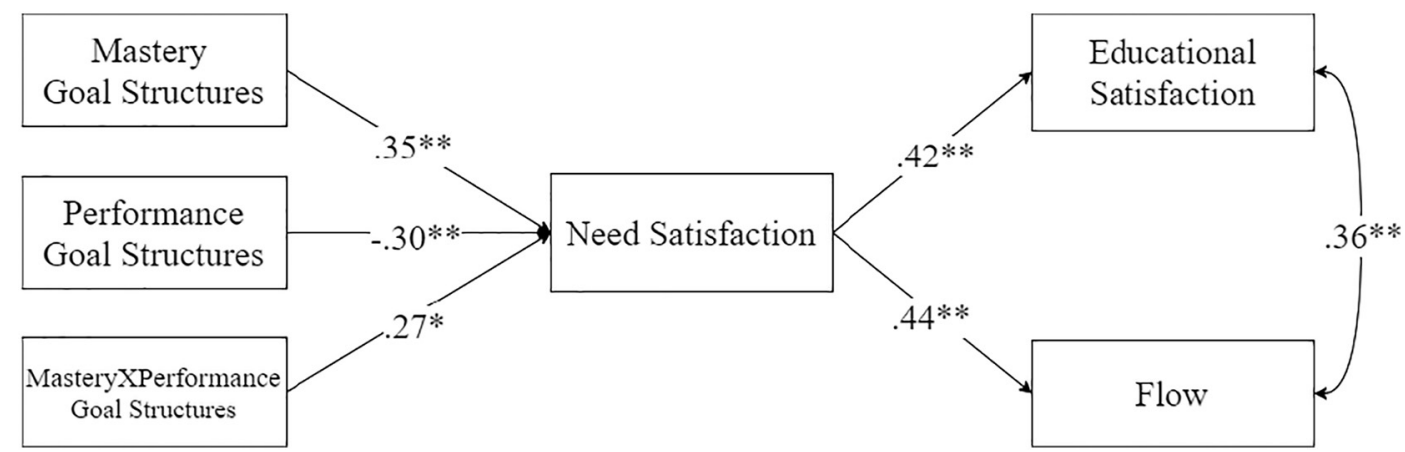

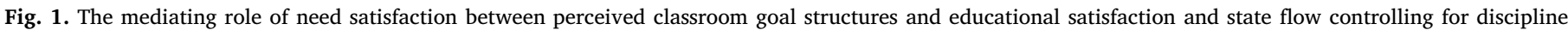
differences and age (not shown for sake of clarity).

Note. ${ }^{*} p<.05$. ${ }^{* *} p<.01$. Explained variance for need satisfaction is $R^{2}=0.15$, for educational satisfaction is $R^{2}=0.20$ and for flow is $R^{2}=0.24$.

and state flow (MLM: $B=0.07, S E=0.03, z=2.03, \quad \beta=0.12$, $p<.05$; Bootstrap: 95\%-CI: 0.01-0.12). This means that high MGSs attenuated the negative relationship between PGSs and educational satisfaction as well as state flow through need satisfaction.

\subsection{Brief discussion}

The purpose of this study was to investigate, whether students' need satisfaction serves as a mediator between perceived classroom goal structures and educational satisfaction and flow.

In line with the predictions, we found that perceived MGSs were positively related to students' need satisfaction, while PGSs were negatively related to students' need satisfaction (Hypothesis 1). We also found a positive relation between need satisfaction and the interaction of MGSs and PGSs suggesting that, when perceived MGSs were high as compared to when MGSs were low, the negative relation between PGSs and need satisfaction was attenuated. This finding supports Hypothesis 2. Finally, aligned with Hypothesis 3, we found that MGSs positively predicted educational satisfaction and state flow through need satisfaction, while PGSs negatively predicted educational satisfaction and state flow through need satisfaction.

While our predictions have been confirmed, it is worthy to note that, in the correlation table, classroom goals structures were appeared to be unrelated to educational satisfaction and flow despite findings of other studies that show a positive relation between them (e.g., Harwood et al., 2015). Our assumption is that this result is due to the different level to which students referred when they reported classroom goal structures, need satisfaction and optimal educational experiences. Classroom goal structures were assessed with reference to a specific course, while need satisfaction, flow and educational satisfaction were assessed with reference to their university education in general. Therefore, the full mediation of need satisfaction between classroom goal structures and optimal educational experience could occur due to a general level of assessment of the outcomes. To test this possibility and to address the issue of a large number of missing values in our dataset, we set up Study 2 .

\section{Study 2}

Study 2 was almost identical to Study 1 with two exceptions: (a) 


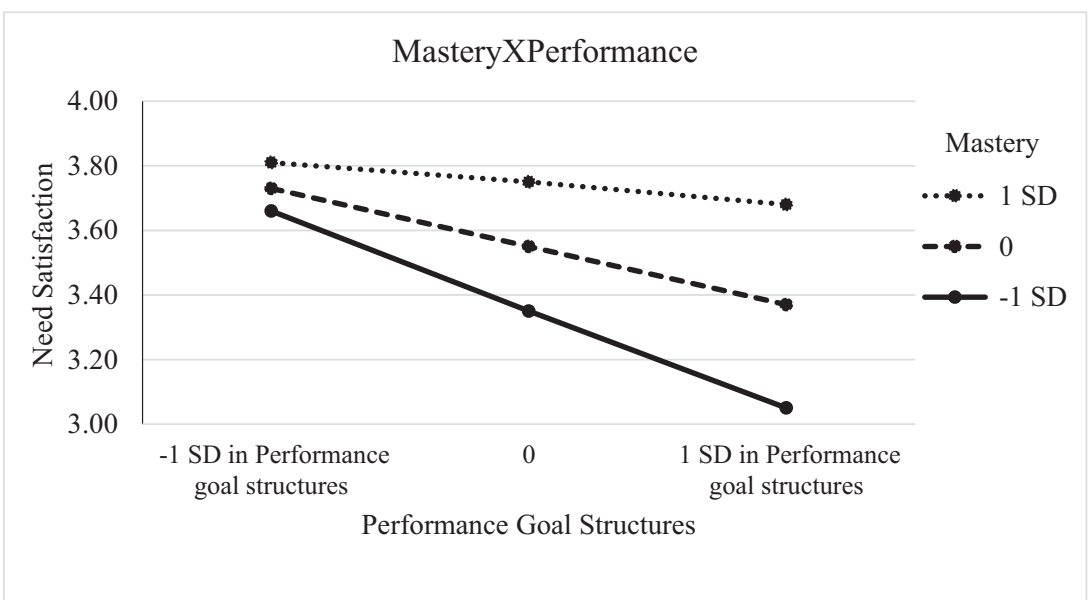

Fig. 2. Moderated effects of MGSs on the relationship between PGSs and need satisfaction.

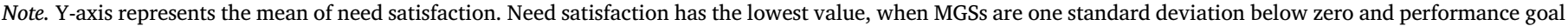
structures are high.

Table 3

CFA results and Cronbach alphas of the measured variables in Study 2.

\begin{tabular}{|c|c|c|c|c|c|c|c|}
\hline Variables & $\alpha$ & $\chi^{2}$ & $d f$ & CFI & RMSEA & SRMR & $\% 90-C I$ \\
\hline $\begin{array}{c}\text { Classroom } \\
\text { goal } \\
\text { struc- } \\
\text { tures }\end{array}$ & $\begin{array}{l}\alpha_{\mathrm{M}}=0.87 \\
\alpha_{\mathrm{P}}=0.69\end{array}$ & 84.291 & 34 & 0.929 & 0.076 & 0.072 & $0.063-0.109$ \\
\hline $\begin{array}{l}\text { Need } \\
\text { satisfac- } \\
\text { tion }\end{array}$ & $\alpha=0.84$ & 60.834 & 24 & 0.961 & 0.078 & 0.056 & $0.057-0.108$ \\
\hline State flow & $\alpha=0.83$ & 66.341 & 26 & 0.939 & 0.078 & 0.046 & $0.060-0.110$ \\
\hline Vitality & $\alpha=0.91$ & 0.192 & 2 & 1.000 & 0.000 & 0.003 & $0.000-0.056$ \\
\hline
\end{tabular}

Note. $\alpha_{M}=$ Cronbach alpha for MGSs, $\alpha_{\mathrm{p}}=$ Cronbach alpha for PGSs. The presented CFA results for state flow were obtained after permitting two items to covary.

Need satisfaction and optimal educational experience were assessed with reference to the specific course for which the classroom goal structures were also assessed. (b) In order to specify optimal educational experience to a course level, we replaced educational satisfaction to vitality which is also considered as an indicator of optimal experience (Ryan \& Deci, 2001). This is because educational satisfaction by nature refers to educational life in general while vitality can refer to a specific course. We believe that an assessment of the need satisfaction and optimal experience at the specific course level depict more reliably the mediating role of need satisfaction between classroom goal structures and educational experience.

In Study 2, in order to address the issue of a large number of missing values of Study 1, we administrated the survey online and submission would not be possible if all the questions were not answered. To avoid, however, random answers, in the online battery of the questionnaires, we included an item asking from the participants to give a specific answer. Students who did not give this answer were excluded from the analysis.

\subsection{Method}

\subsubsection{Participants and procedure}

Participants were initially 277 Turkish university students from a private non-profit university in an urban area of Turkey. However, 22 of them were excluded due to their wrong answer to the checking item. The final sample consisted of 255 (45\% females, $M_{\text {age }}=19.75$, $S D=1.67)$ students. Sixty-one students came from social science while 193 students came from engineering and sciences ( 1 student omitted to reply). As in Study 1, all the ethical procedures according to human subjects' principles were applied in Study 2. A research assistant administered in class-sessions an online survey for about $10 \mathrm{~min}$. Participants reported their need satisfaction, flow, vitality and the classroom goal structures of the specific course during which the data were collected (i.e., Algorithms and Programming I, Introduction to Psychology, Introduction to Programming, Introduction to World Politics and Calculus I). The courses to which the students referred were either obligatory or elective.

\subsubsection{Measures}

The same instruments of Study 1 were used to measure classroom goal structures, need satisfaction and state flow. Additionally, four items from the Subjective Vitality Scale (Ryan \& Frederick, 1997) were used to assess students' subjective vitality (e.g. "I feel alive and vital"). CFA results and Cronbach alphas of the measured variables are presented in Table 3.

\subsubsection{Plan of analysis}

The same plan of analysis as in Study 1 was followed.

\subsection{Results}

\subsubsection{Preliminary analysis}

Descriptive statistics and bivariate correlations among the measured and background variables are presented in Table 4. As it is indicated in Table 4, MGSs were positively related (and PGSs unrelated) to need satisfaction, state flow and vitality.

MANOVA did not yield any gender differences but it showed a significant difference between social sciences and engineering - sciences (Wilk's $\Lambda=0.920, F[5,248]=4.33, p<.01$, multivariate $\eta^{2}=0.08$ ). Taking into consideration this difference, as well as that age was significantly correlated with perceived MGSs, discipline and age were included as a covariate in the subsequent analyses.

\subsubsection{Main analysis}

A path analysis to test our hypotheses yielded the following fit indices S-B $\chi^{2}(6, N=254)=30.45, p^{<} .01 . \mathrm{CFI}=0.935$, SRMR $=0.044$, RMSEA $=0.127$ (90\%-CI: 0.084-0.173). However, inspection of modification indices suggested direct paths from perceived MGSs to vitality and state flow to further improve the model's fit. By adding these paths, we obtained the following fit indices: $\mathrm{S}-\mathrm{B} \chi^{2}(4, N=254)=9.36$, $p^{<} .01 . \quad$ CFI $=0.986, \quad$ SRMR $=0.025, \quad$ RMSEA $=0.073 \quad(90 \%-C I$ : 0.0.000-0.134). As Fig. 3 shows perceived MGSs were positively related 
Table 4

Means, standard deviations and bivariate correlations of the measured variables in Study 2 .

\begin{tabular}{|c|c|c|c|c|c|c|c|c|}
\hline Variables & 1 & 2 & 3 & 4 & 5 & 6 & 7 & 8 \\
\hline \multicolumn{9}{|l|}{ Background variables } \\
\hline 1. Age & 1 & & & & & & & \\
\hline 2. Gender & $-0.19^{* *}$ & 1 & & & & & & \\
\hline 3. Discipline & $-0.51^{* *}$ & $0.28^{* *}$ & 1 & & & & & \\
\hline \multicolumn{9}{|l|}{ Independent variables } \\
\hline 4. MGSs & $-0.35^{* *}$ & 0.04 & $0.18^{* *}$ & 1 & & & & \\
\hline 5. PGSs & -0.07 & -0.04 & 0.09 & $0.20 * *$ & 1 & & & \\
\hline \multicolumn{9}{|l|}{ Dependent variables } \\
\hline 6. Need satisfaction & -0.02 & 0.09 & -0.05 & $0.41 * *$ & 0.05 & 1 & & \\
\hline 7. Flow & 0.07 & $0.14^{*}$ & -0.11 & $0.34 * *$ & -0.05 & $0.68^{* * *}$ & 1 & \\
\hline 8. Vitality & 0.02 & 0.10 & -0.12 & $0.42^{* *}$ & -0.03 & $0.58^{* *}$ & $0.65^{* *}$ & 1 \\
\hline$M$ & 19.75 & 0.55 & 0.76 & 3.95 & 2.86 & 3.53 & 3.53 & 2.97 \\
\hline$S D$ & 1.67 & 0.50 & 0.43 & 0.87 & 0.85 & 0.77 & 0.72 & 1.12 \\
\hline
\end{tabular}

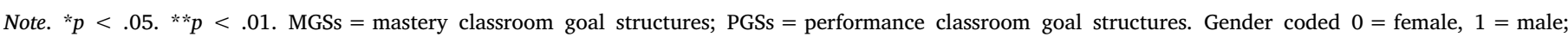
Discipline coded $0=$ social sciences, 1 = engineering and sciences.

to need satisfaction (MLM: $\beta=0.48, p<.01$; Bootstrap: 95\%-CI: $0.32-0.53$ ). However, perceived PGSs and the interaction between perceived MGSs and PGSs were not significantly related to need satisfaction. Partially supporting our Hypothesis 1, it seems that when university students perceive a learning orientation in classroom goal structures, they also report high level of need satisfaction.

Both state flow and vitality were positively related to need satisfaction (MLM: $\beta=0.63, p<.01$; Bootstrap: 95\%-CI: $0.49-0.68$ and MLM: $\beta=0.46, p<.01$; Bootstrap: 95\%-CI: 0.52-0.82 respectively). A test of indirect effects showed that need satisfaction was mediated the relationship between perceived MGSs and flow (MLM: $B=0.25$, $S E=0.38, z=6.48, \beta=0.30, p<.01$; Bootstrap: 95\%-CI: 0.17-0.32) and between MGSs and vitality (MLM: $B=0.28, S E=0.05, z=5.67$, $\beta=0.22, p<.01$; Bootstrap: 95\%-CI: 0.19-0.38). In addition, MGSs were directly related to flow (MLM: $\beta=0.12, p<.05$; Bootstrap: $95 \%$ CI: $0.02-0.19$ ) and vitality (MLM: $\beta=0.27, p<.01$; Bootstrap: 95\%CI: 0.20-0.48).

\subsection{Brief discussion}

The purpose of this study was to investigate the mediating role of need satisfaction between perceived classroom goal structures and optimal educational experience after addressing methodological weaknesses of Study 1. Specifically, in this study, we asked students to report their perceived classroom goal structures, need satisfaction and vitality and state flow in the framework of a specific course than in their education in general.

We found that perceived MGSs were positively related to students' need satisfaction. This finding partially supported Hypothesis 1 as PGSs were not related to need satisfaction. When students reported their need satisfaction at the specific level at which the goal structures had been also reported, PGSs were not a significant negative predictor of need satisfaction as it was the case in Study 1 . Research in sport context has shown that performance-focused climate is either negatively related to the fulfillment of need for relatedness and autonomy (Harwood et al., 2015; Quested \& Duda, 2009) or, similar to the results of Study 2, unrelated to the fulfillment of need for autonomy and competence (Quested \& Duda, 2009). Reinboth and Duda (2006) also showed that ego involving coaching climate failed to negatively predict changes in competence, autonomy and coach-related relatedness satisfaction. It seems, therefore, that the research findings, neither in sport nor in educational context are consistent about a negative relation of PGSs and need satisfaction although they clearly show that PGSs do not satisfy people's psychological needs. Since in our study we investigated the need satisfaction as a composite variable, future research is necessary to examine the relationship between classroom goal structures and the three separate psychological needs in educational settings.

The results of Study 2 did not also support our assumption that MGSs will attenuate the negative relationship between PGSs and need satisfaction (Hypothesis 2) as it is shown by the non-significant relation between the interaction of MGSs and PGSs and need satisfaction. This result seems logical as PGSs was not also related to need satisfaction in this study.

Finally, in partial support of Hypothesis 3, we found that need satisfaction partially mediated the relationship between MGSs and state flow and vitality. MGSs were also directly related to the indicators of optimal educational experience. When the climate of a specific course focuses on learning and self-improvement, students' psychological

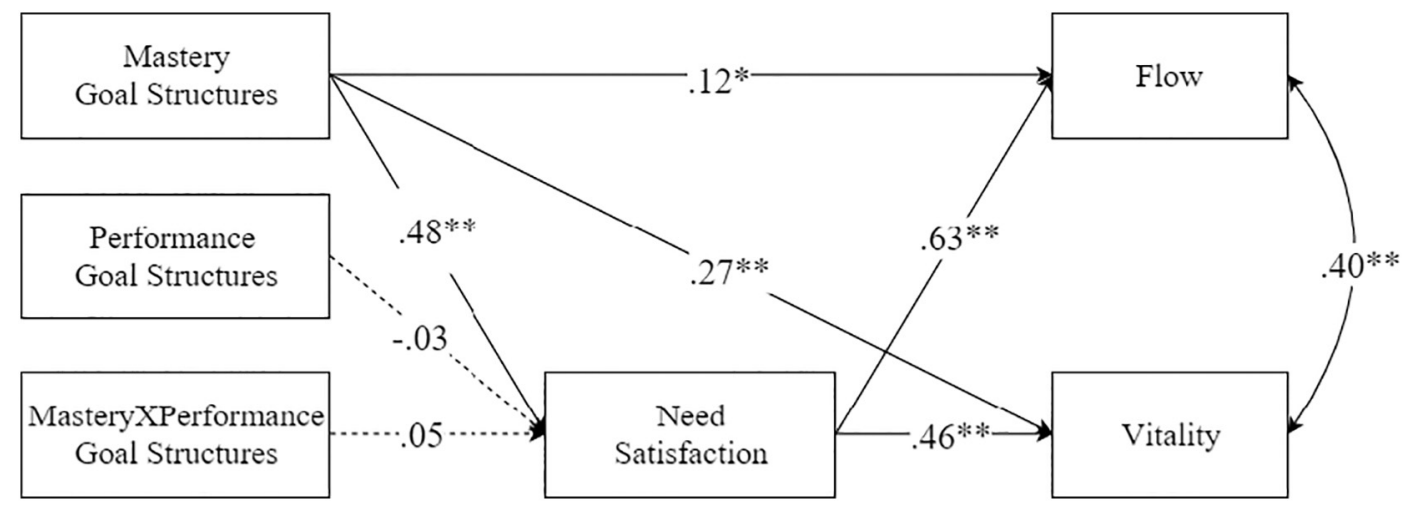

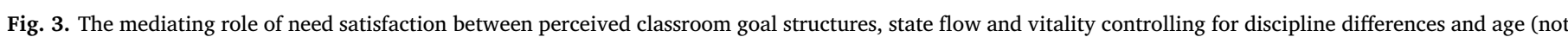
shown for sake of clarity).

Note. ${ }^{*} p<.05$. ${ }^{* *} p<.01$. Explained variance for need satisfaction is $R^{2}=0.19$, for flow is $R^{2}=0.47$ and for vitality is $R^{2}=0.39$. 
needs at this course are satisfied, while the learning-focused climate promote also students' vitality and experience of flow at this course. The findings of Study 2 showed that perceived MGSs are important for satisfying students' psychological needs and promoting their optimal educational experience.

\section{Discussion}

The purpose of these studies was to investigate, whether students' need satisfaction serves as a mediator between perceived classroom goal structures and educational satisfaction or vitality and flow. Thus, we, first, examined whether perceived MGSs and PGSs are positively and negatively respectively related to students' need satisfaction. We, then, examined, whether high perceived MGSs attenuate the negative relationship between PGSs and need satisfaction. Finally, we examined the extent to which classroom goal structures have indirect effects on educational satisfaction or vitality and state flow through need satisfaction.

In line with the predictions, in Study 1, we found that perceived MGSs and PGSs were positively and negatively related to students' need satisfaction, respectively (Hypothesis 1 ). However, in partially support of Hypothesis 1, in Study 2, we found only perceived MGSs to be positively related to students' need satisfaction. The main message from both studies is that, when students perceive that they can organize their learning according to their own abilities and preferences and this selfreferenced improvement is respected by their educational environment (i.e. perceived MGSs), their psychological needs are more likely to be satisfied. This result supports previous findings in laboratory studies or sport settings. For instance, Standage et al. (2005) found that a masteryoriented environment during a laboratory co-ordination task was positively related to participants' need satisfaction and subjective wellbeing. Similarly, Reinboth and Duda (2006) found that task involving coaching climate (i.e., a climate focused on the task at hand and selfimprovement) positively predicts need satisfaction at the end of the training period.

In contrast, when the classroom focuses on grades and outperforming others, students feel as opponents of their peers and in a situation to protect and prove their competence. In such an environment, there is not enough space for sharing with others, self-initiation in learning and feelings of effectiveness unrelated to others performance. Our findings suggest that, when students perceive high PGSs, students' psychological needs are less likely to be satisfied. Previous research in sport context also showed either a negative relation between ego-involving interpersonal context and participants' need satisfaction (Harwood et al., 2015; Standage et al., 2005) or no relation between them (Quested \& Duda, 2009; Reinboth \& Duda, 2006).

Regarding our assumption that perceived MGSs will attenuate any negative relationship between perceived PGSs and need satisfaction; this was true in Study 1, where the negative relation did exist. However, it was not true in Study 2, where these two variables were unrelated. These findings partially support our Hypotheses 2 and show that MGSs are sufficient for students' need satisfaction as Peng et al.'s (2013) had also shown. This is because the positive interaction between MGSs and PGSs in Study 1, shows that, when students perceived high both types of classroom goal structures, they reported either approximately the same amount of need satisfaction compared to when they perceived only high MGSs or higher need satisfaction compared to when they perceived only high PGSs. The results of both Study 1 and 2 do not support the superiority of multiple goals structures for students need satisfaction. The message, therefore, for educators and policy makers is that the MGSs make the difference in the satisfaction of students' psychological needs.

Aligned with Hypothesis 3, we found that MGSs positively predicted educational satisfaction and state flow as well as vitality through need satisfaction. On the other hand, PGSs either negatively predicted educational satisfaction and state flow through need satisfaction (Study 1) or were unrelated to optimal educational experience (Study 2). It is important to note also that MGSs were directly related to both state flow and vitality. These findings suggest that, if classrooms focus on learning and understanding, students' psychological needs are satisfied and they experience high educational satisfaction, state flow and vitality. In contrast, if classrooms focus on students' performance and competition only, students' psychological needs are not satisfied and their optimal educational experience is either low or totally unrelated to the competition classroom goal messages. It seems that need satisfaction is one of the mediators that links MGSs with students' educational outcomes, while, at the same time, MGSs can be also positively and directly related to educational experience. As for the PGSs, they do not appear to be steadily related to optimal educational experience through need satisfaction. This finding suggests that PGSs might be steadier predictors for other educational outcomes than vitality and state flow and might follow a different pathway to these educational outcomes compared to MGSs. Recently, Mouratidis, Michou, Dermiciouglu, and Sayil (2018) found that while MGSs predict math grades through personal mastery goals and challenge-seeking, PGSs predict math grades only through personal performance-approach goals. Challenge-seeking is an optimal educational experience with which PGSs are not related to predict through them students' performance. Further research, therefore, is needed to clarify to what extent mediators between PGSs and educational outcomes as well as their direct relations are different from the mediators between MGSs and educational outcomes as well as their direct relations.

The findings of the present study as a whole support Urdan's (2010) suggestion that research outside of the Achievement Goal Theory framework, could enrich the description of the classroom environment that is adaptive for student development. The findings of our study also show that some constructs of the Achievement Goal Theory can be complemented by constructs of the Self Determination Theory in explaining learning and development and, as several other recent studies have indicated (e.g., Benita, Roth, \& Deci, 2014; Ciani, Sheldon, Hilpert, \& Easter, 2011; Madjar, Nave, \& Hen, 2013; Michou, Vansteenkiste, Mouratidis, \& Lens, 2014; Vansteenkiste, Lens, Elliot, Soenens, \& Mouratidis, 2014), research on the intersection of the two theories could be promising for a better understanding of achievement striving.

Our findings also extend previous research that has shown a needsupportive university classroom environment to be linked to positive educational outcomes through need satisfaction (e.g., Tze, Klassen, \& Daniels, 2014). They suggest that additional to need-supportive environment MGSs (emphasis on learning, understanding and self-improvement) are also important for students' subjective-well-being and optimal educational experience. Moreover, our findings suggest that PGSs are either negatively related or unrelated to students' psychological needs and either negatively related or unrelated to optimal educational experience. This is an important element to be taken into consideration by teachers, who sometimes promote competition and normative success in the classroom as a means to foster students' performance. Research provides evidence that, indeed, when students endorse performance goals promoted by the environment, they may get high grades at school (Hulleman, Schrager, Bodmann, \& Harackiewicz, 2010). However, as our findings showed, a performance-oriented environment is not beneficial for students' psychological needs, students' satisfaction at school, flow during homework and vitality. Teachers should not ignore the cost of their focus on normative success and high grades for students' subjective well-being and optimal educational experience. Future research could investigate how teachers' approaches for students' autonomy support described by the SDT perspective (see Reeve, 2006) can be combined with non-normative evaluation and learning-focused messages described by the AGT framework (Meece et al., 2006) in order to satisfy students psychological needs.

Our study, however, has some limitations that should be taken into consideration when discussing the findings. Firstly, a cross-sectional 
design was adopted and all measures in the study were self-reported. Therefore, this study did not investigate any causal relationship between the studied variables, and the information related to the classroom goal structures was not cross-checked by third part's assessments (e.g., teachers' or observers' perception about the classroom goal structures).

Second, the samples were recruited from one university in Turkey and therefore, it remains to be seen whether or not the results can be generalized for other cultures or age groups (e.g., high school or middle school students). Therefore, further research is necessary with bigger samples from different institutions and countries as well as longitudinal or experimental design to capture the causal relationship of the educational environment to students' outcomes through need satisfaction. It is true that we cannot exclude the case that students' need satisfaction or educational experience influences their perception of the classroom environment. Moreover, as Turner, Gray, Anderman, Dawson, and Anderman (2013) found that perceptions of classroom goal structures changes over time, longitudinal studies could also clarify to what extent the relationship between classroom goal structures and need satisfaction changes over time.

Fourth, since classroom goal structures are contextual constructs, class-level differences could occur. In this study, we did not consider to what extent classroom goal structures at the class level predict need satisfaction and educational outcomes. Regarding this issue, further research is needed with bigger samples nested in sufficient number of classrooms for multi-level analysis.

Fifth, in Study 1, neither the internal consistency nor the CFA for the need frustration subscales was acceptable so as to examine its mediating role between classroom goal structures and educational experience. In Study 2 also, we did not assess need frustration as we were interested in replicating the results of Study 1 while addressing methodological weaknesses. Future research could investigate whether PGSs are positively related to need frustration and to what extent this relationship can be attenuated by MGSs so as to clarify the role of a competitive climate on students' well-being. Future research could also investigate the relationship of the satisfaction or frustration of the three psychological needs separately to classroom goal structures and educational outcomes to depict a more refined picture. To this end, especially in studies with Turkish samples, the low internal consistency of autonomy satisfaction ( $\alpha=0.57$ Study $1 ; \alpha=0.58$ Study 2 ) in the present studies should be considered. Finally, previous research has shown that achievement goals are mediators between perceptions of classroom environment and educational outcomes (e.g., Church, Elliot, \& Gable, 2001) as well as that motivation is a mediator between need satisfaction and outcomes (McDonough \& Crocker, 2007; Mouratidis, Vansteenkiste, Lens, \& Sideridis, 2008; Niemiec \& Ryan, 2009). Therefore, future research should also include motivation in another mediating level between need satisfaction and educational outcomes.

In conclusion, this study highlighted need satisfaction as a psychological mediator that relates MGSs to learners' subjective-well-being and optimal educational experience. In doing so, this study also provides evidence to teachers about the benefits of MGSs for students need satisfaction, vitality, flow in subject-related tasks and educational satisfaction. Current findings suggest that future intervention programs which aim to increase students' optimal educational experience should focus, among other practices, on diminishing PGSs and enhancing the provision of mastery goals in the classroom environment.

\section{Acknowledgement}

We are very thankful to Asst. Prof. Dr. Athanasios Mouratidis for his advices in the statistical analysis.

\section{References}

Adie, J. W., Duda, J. L., \& Ntoumanis, N. (2012). Perceived coach-autonomy support, basic need satisfaction and the well-and ill-being of elite youth soccer players: A longitudinal investigation. Psychology of Sport and Exercise, 13, 51-59. http://dx.doi. org/10.1016/j.psychsport.2011.07.008.

Ames, C. (1992). Classrooms: Goals, structures, and student motivation. Journal of Educational Psychology, 84, 261-271. http://dx.doi.org/10.1037//0022-0663.84.3. 261.

Anderman, E. M., \& Midgley, C. (1997). Changes in achievement goal orientations, perceived academic competence, and grades across the transition to middle-level schools. Contemporary Educational Psychology, 22, 269-298. http://dx.doi.org/10. 1006/ceps.1996.0926.

Benita, M., Roth, G., \& Deci, E. L. (2014). When are mastery goals more adaptive? It depends on experiences of autonomy support and autonomy. Journal of Educational Psychology, 106, 258-267. http://dx.doi.org/10.1037/a0034007.

Church, M. A., Elliot, A. J., \& Gable, S. L. (2001). Perceptions of classroom environment, achievement goals, and achievement outcomes. Journal of Educational Psychology, 93, 43-54. http://dx.doi.org/10.1037/0022-0663.93.1.43.

Ciani, K. D., Sheldon, K. M., Hilpert, J. C., \& Easter, M. A. (2011). Antecedents and trajectories of achievement goals: A self-determination theory perspective. British Journal of Educational Psychology, 81, 223-243. http://dx.doi.org/10.1348/ $000709910 X 517399$

Covington, M. V. (2000). Goal theory, motivation, and school achievement: An integrative review. Annual Review of Psychology, 51, 171-200. http://dx.doi.org/10. 1146/annurev.psych.51.1.171.

Csikszentmihalyi, M. (1990). Flow: The psychology of optimal experience. New York, NY Harper \& Row.

Csikszentmihalyi, M. (1997). Flow and education. NAMTA Journal, 22, 2-35.

Deci, E. L., \& Ryan, R. M. (2000). The "what" and "why" of goal pursuits: Human needs and the self-determination of behavior. Psychological Inquiry, 11, 227-268. http://dx doi.org/10.1207/S15327965PLI1104 01.

Demirbatir, R. E. (2015). Relationships between psychological well-being, happiness, and educational satisfaction in a group of university music students. Educational Research Review, 10, 2198-2206.

Diener, E. (1984). Subjective well-being. Psychological Bulletin, 95, 542-575. http://dx. doi.org/10.1037/0033-2909.95.3.542.

Diener, E. D., Emmons, R. A., Larsen, R. J., \& Griffin, S. (1985). The satisfaction with life scale. Journal of Personality Assessment, 49, 71-75. http://dx.doi.org/10.1207/ s15327752jpa4901_13.

Elliot, A. J., \& Dweck, C. S. (2005). Competence and motivation. In A. Elliot, \& C. Dweck (Eds.). Handbook of competence and motivation (pp. 3-12). New York: Guilford Press.

Fairchild, A. J., \& MacKinnon, D. P. (2009). A general model for testing mediation and moderation effects. Prevention Science, 10, 87-99. http://dx.doi.org/10.1007/ s11121-008-0109-6.

Fast, L. A., Lewis, J. L., Bryant, M. J., Bocian, K. A., Cardullo, R. A., Rettig, M., \& Hammond, K. A. (2010). Does math self-efficacy mediate the effect of the perceived classroom environment on standardized math test performance? Journal of Educational Psychology, 102, 729-740. http://dx.doi.org/10.1037/a0018863.

Frazier, P. A., Tix, A. P., \& Barron, K. E. (2004). Testing moderator and mediator effects in counseling psychology research. Journal of Counseling Psychology, 51, 115-134. http://dx.doi.org/10.1037/0022-0167.51.1.115.

Gagne, M., Ryan, M. R., \& Bergman, K. (2003). Autonomy support and need satisfaction in the motivation and well-being of gymnasts. Journal of Applied Sport Psychology, 15, 372-390. http://dx.doi.org/10.1080/714044203.

Haerens, L., Aelterman, N., Vansteenkiste, M., Soenens, B., \& Van Petegem, S. (2015). Do perceived autonomy-supportive and controlling teaching relate to physical education students' motivational experiences through unique pathways? Distinguishing between the bright and dark side of motivation. Psychology of Sport and Exercise, 16, 26-36. http://dx.doi.org/10.1016/j.psychsport.2014.08.013.

Hambleton, R. K. (1994). Guidelines for adapting educational and psychological tests: A progress report. European Journal of Psychological Assessment, 10, 229-240.

Haq, R., \& Zia, U. (2013). Multidimensional wellbeing: An index of quality of life in a developing economy. Social Indicators Research, 114, 997-1012. http://dx.doi.org/ 10.1007/s11205-012-0186-6.

Harwood, C. G., Keegan, R. J., Smith, J. M., \& Raine, A. S. (2015). A systematic review of the intrapersonal correlates of motivational climate perceptions in sport and physical activity. Psychology of Sport and Exercise, 18, 9-25. http://dx.doi.org/10.1016/j. jsams. 2014.11.074.

Hu, L., \& Bentler, P. (1995). Evaluating model fit. In R. H. Hoyle (Ed.). Structural equation modeling. Concepts, issues, and applications (pp. 76-99). London: Sage.

Hu, L. T., \& Bentler, P. M. (1999). Cutoff criteria for fit indexes in covariance structure analysis: Conventional criteria versus new alternatives. Structural Equation Modeling: A Multidisciplinary Journal, 6, 1-55. http://dx. doi.org/10.1080/ 10705519909540118.

Hulleman, C. S., Schrager, S. M., Bodmann, S. M., \& Harackiewicz, J. M. (2010). A metaanalytic review of achievement goal measures: Different labels for the same constructs or different constructs with similar labels? Psychological Bulletin, 136, 422-449. http://dx.doi.org/10.1037/a0018947.

Jackson, S. A., \& Eklund, R. C. (2002). Assessing flow in physical activity: The Flow State Scale-2 and Dispositional Flow Scale-2. Journal of Sport and Exercise Psychology, 24, 133-150. http://dx.doi.org/10.1123/jsep.24.2.133.

Jackson, S. A., \& Marsh, H. W. (1996). Development and validation of a scale to measure optimal experience: The Flow State Scale. Journal of Sport and Exercise Psychology, 18, 17-35. http://dx.doi.org/10.1123/jsep.18.1.17.

Kaplan, A., \& Midgley, C. (1999). The relationship between perceptions of the classroom goal structure and early adolescents' affect in school: The mediating role of coping strategies. Learning and Individual Differences, 11, 187-212. http://dx.doi.org/10. 1016/S1041-6080(00)80005-9.

Kline, R. B. (2011). Principles and practice of structural equation modeling. New York: Guilford Press.

Linnenbrink, E. A. (2005). The dilemma of performance-approach goals: The use of multiple goal contexts to promote students' motivation and learning. Journal of 
Educational Psychology, 97(2), 197-213. http://dx.doi.org/10.1037/0022-0663.97.2. 197.

Madjar, N., \& Cohen-Malayev, M. (2013). Youth movements as educational settings promoting personal development: Comparing motivation and identity formation in formal and non-formal education contexts. International Journal of Educational Research, 62, 162-174. http://dx.doi.org/10.1016/j.ijer.2013.09.002.

Madjar, N., Nave, A., \& Hen, S. (2013). Are teachers' psychological control, autonomy support and autonomy suppression associated with students' goals? Educational Studies, 39, 43-55. http://dx.doi.org/10.1080/03055698.2012.667871.

Matos, L., Lens, W., Vansteenkiste, M., \& Mouratidis, A. (2017). Optimal motivation in Peruvian high schools: Should learners pursue and teachers promote mastery goals, performance-approach goals or both? Learning and Individual Differences, 55, 87-96. http://dx.doi.org/10.1016/j.lindif.2017.02.003.

Mavor, K. I., Platow, M. J., \& Bizumic, B. (2017). Self and social identity in educational contexts. New York, USA: Routledge.

McDonough, M. H., \& Crocker, P. R. (2007). Testing self-determined motivation as a mediator of the relationship between psychological needs and affective and behavioral outcomes. Journal of Sport and Exercise Psychology, 29, 645-663. http://dx.doi. org/10.1123/jsep.29.5.645.

Meece, J. L. (1991). The classroom context and student motivational goals. In M. L Maehr, \& P. R. Pintrich (Vol. Eds.), Advances in motivation and achievement. Vol. 7. Advances in motivation and achievement (pp. 261-285). Greenwich, CT: JAI Press.

Meece, J. L., Anderman, E. M., \& Anderman, L. H. (2006). Classroom goal structure, student motivation, and academic achievement. Annual Review of Psychology, 57, 487-503. http://dx.doi.org/10.1146/annurev.psych.56.091103.070258.

Michalos, A. C. (2012). Global report on student well-being: Volume IV: Religion, education, recreation, and health. Springer Science \& Business Media.

Michou, A., Mouratidis, A., Lens, W., \& Vansteenkiste, M. (2013). Personal and contextual antecedents of achievement goals: Their direct and indirect relations to students learning strategies. Learning and Individual Differences, 23, 187-194. http://dx.doi. org/10.1016/j.lindif.2012.09.005.

Michou, A., Vansteenkiste, M., Mouratidis, A., \& Lens, W. (2014). Enriching the hier archical model of achievement motivation: Autonomous and controlling reasons underlying achievement goals. British Journal of Educational Psychology, 84, 650-666. http://dx.doi.org/10.1111/bjep.12055.

Midgley, C., Kaplan, A., Middleton, M., Maehr, M. L., Urdan, T., Anderman, L. H., ... Roeser, R. (1998). The development and validation of scales assessing students' achievement goal orientations. Contemporary Educational Psychology, 23, 113-131. http://dx.doi.org/10.1006/ceps.1998.0965.

Midgley, C., Maehr, M. L., Hruda, L. Z., Anderman, E., Anderman, L., Freeman, K. E., .. Urdan, T. (2000). Manual for the patterns of adaptive learning scales. Ann Arbor, 1001, 48109-1259. http://dx.doi.org/10.1037/t19870-000.

Miki, K., \& Yamauchi, H. (2005). Perceptions of classroom goal structures, personal achievement goal orientations, and learning strategies. Japanese Journal of Psychology, 76, 260-268. http://dx.doi.org/10.4992/jjpsy.76.260.

Mouratidis, A., Michou, A., Dermiciouglu, A., \& Sayil, M. (2018). Different goals, different pathways to success: Performance-approach goals as direct and mastery-approach goals as indirect predictors of grades in mathematics. Learning and Individual Differences, 61, 127-135. http://dx.doi.org/10.1016/j.lindif.2017.11.017.

Mouratidis, A., Vansteenkiste, M., Lens, W., \& Sideridis, G. (2008). The motivating role of positive feedback in sport and physical education: Evidence for a motivational model. Journal of Sport and Exercise Psychology, 30, 240-268. http://dx.doi.org/10.1123/ jsep.30.2.240.

Mouratidis, A., Vansteenkiste, M., Michou, A., \& Lens, W. (2013). Perceived structure and achievement goals as predictors of students' self-regulated learning and affect and the mediating role of competence need satisfaction. Learning and Individual Differences, 23, 179-186. http://dx.doi.org/10.1016/j.lindif.2012.09.001.

Murayama, K., \& Elliot, A. J. (2009). The joint influence of personal achievement goals and classroom goal structures on achievement-relevant outcomes. Journal of Educational Psychology, 101, 432-447. http://dx.doi.org/10.1037/a0014221.

Nicholls, J. G. (1984). Achievement motivation: Conceptions of ability, subjective experience, task choice, and performance. Psychological Review, 91, 328-346. http://dx. doi.org/10.1037/0033-295X.91.3.328.

Niemiec, C. P., \& Ryan, R. M. (2009). Autonomy, competence, and relatedness in the classroom. Applying self-determination theory to educational practice. Theory and Research in Education, 7, 133-144. http://dx.doi.org/10.1177/1477878509104318.

Patrick, H., \& Ryan, A. M. (2005). Identifying adaptive classrooms: Dimensions of the classroom social environment. In K. A. Moore, \& L. H. Lippman (Eds.). What do children need to flourish?: Conceptualizing and measuring indicators of positive development (pp. 271-287). New York: Springer.

Pelletier, L. G. (2002). A motivational analysis of self-determination for pro-environmental behaviors. In E. L. Deci, \& R. M. Ryan (Eds.). Handbook of self-determination research (pp. 205-232). Rochester, NY: University of Rochester Press.

Peng, S. L., Cherng, B. L., \& Chen, H. C. (2013). The effects of classroom goal structures on the creativity of junior high school students. Educational Psychology, 33, 540-560. http://dx.doi.org/10.1080/01443410.2013.812616.

Quested, E., \& Duda, J. L. (2009). Perceptions of the motivational climate, need satisfaction, and indices of well-and ill-being among hip hop dancers. Journal of Dance Medicine \& Science, 13, 10-19. http://dx.doi.org/10.1016/j.psychsport.2005.06.002.

Reeve, J. (2006). Teachers as facilitators: What autonomy-supportive teachers do and why their students benefit. The Elementary School Journal, 106, 225-236. http://dx. doi.org/10.1086/501484.

Reeve, J. (2009). Why teachers adopt a controlling motivating style toward students and how they can become more autonomy supportive. Educational Psychologist, 44, 159-175. http://dx.doi.org/10.1080/00461520903028990.
Reinboth, M., \& Duda, J. L. (2006). Perceived motivational climate, need satisfaction and indices of well-being in team sports: A longitudinal perspective. Psychology of Sport and Exercise, 7, 269-286. http://dx. doi.org/10.1016/j.psychsport.2005.06.002.

Roeser, R. W., Midgley, C., \& Urdan, T. C. (1996). Perceptions of the school psychological environment and early adolescents' psychological and behavioral functioning in school: The mediating role of goals and belonging. Journal of Educational Psychology, 88, 408-422. http://dx.doi.org/10.1037/0022-0663.88.3.408.

Ryan, R. M., \& Deci, E. L. (2000). Intrinsic and extrinsic motivations: Classic definitions and new directions. Contemporary Educational Psychology, 25, 54-67. http://dx.doi. org/10.1006/ceps.1999.1020.

Ryan, R. M., \& Deci, E. L. (2001). On happiness and human potentials: A review of research on hedonic and eudemonic well-being. Annual Review of Psychology, 52, 141-166. http://dx.doi.org/10.1146/annurev.psych.52.1.141.

Ryan, R. M., \& Frederick, C. (1997). On energy, personality, and health: Subjective vitality as a dynamic reflection of well-being. Journal of Personality, 65(3), 529-565.

Schüler, J., \& Brandstätter, V. (2013). How basic need satisfaction and dispositional motives interact in predicting flow experience in sport. Journal of Applied Social Psychology, 43, 687-705. http://dx.doi.org/10.1111/j.1559-1816.2013.01045.x.

Schüler, J., Brandstätter, V., \& Sheldon, K. M. (2013). Do implicit motives and basic psychological needs interact to predict well-being and flow? Testing a universal hypothesis and a matching hypothesis. Motivation and Emotion, 37, 480-495. http://dx. doi.org/10.1007/s11031-012-9317-2.

Sheldon, K. M., \& Elliot, A. J. (1999). Goal striving, need satisfaction, and longitudinal well-being: The self-concordance model. Journal of Personality and Social Psychology, 76, 482-497. http://dx.doi.org/10.1037//0022-3514.76.3.482.

Sheldon, K. M., \& Hilpert, J. C. (2012). The balanced measure of psychological needs (BMPN) scale: An alternative domain general measure of need satisfaction. Motivation and Emotion, 36, 439-451. http://dx.doi.org/10.1007/s11031-012-9279-4.

Shim, S. S., Cho, Y., \& Wang, C. (2013). Classroom goal structures, social achievement goals, and adjustment in middle school. Learning and Instruction, 23, 69-77. http://dx. doi.org/10.1016/j.learninstruc.2012.05.008.

Skaalvik, E. M., \& Federici, R. A. (2016). Relations between classroom goal structures and students' goal orientations in mathematics classes: When is a mastery goal structure adaptive? Social Psychology of Education, 19, 135-150. http://dx.doi.org/10.1007/ s11218-015-9323-9.

Skaalvik, E. M., \& Skaalvik, S. (2013). School goal structure: Associations with students' perceptions of their teachers as emotionally supportive, academic self-concept, intrinsic motivation, effort, and help seeking behavior. International Journal of Educational Research, 61, 5-14. http://dx.doi.org/10.1016/j.ijer.2013.03.007.

Skinner, E., Furrer, C., Marchand, G., \& Kindermann, T. (2008). Engagement and disaffection in the classroom: Part of a larger motivational dynamic? Journal of Educational Psychology, 100, 765-781. http://dx.doi.org/10.1037/a0012840.

Standage, M., Duda, J. L., \& Ntoumanis, N. (2003). A model of contextual motivation in physical education: Using constructs from self-determination and achievement goal theories to predict physical activity intentions. Journal of Educational Psychology, 95, 97-110. http://dx.doi.org/10.1037//0022-0663.95.1.97.

Standage, M., Duda, J. L., \& Pensgaard, A. M. (2005). The effect of competitive outcome and task-involving, ego-involving, and cooperative structures on the psychological well-being of individuals engaged in a co-ordination task: A self-determination approach. Motivation and Emotion, 29, 41-68. http://dx.doi.org/10.1007/s11031-0054415-z.

Tian, L., Chen, H., \& Huebner, E. S. (2014). The longitudinal relationships between basic psychological needs satisfaction at school and school-related subjective well-being in adolescents. Social Indicators Research, 119, 353-372. http://dx.doi.org/10.1007/ s11205-013-0495-4.

Turner, J. C., Gray, D. L., Anderman, L. H., Dawson, H. S., \& Anderman, E. M. (2013) Getting to know my teacher: Does the relation between perceived mastery goal structures and perceived teacher support change across the school year? Contemporary Educational Psychology, 38, 316-327. http://dx.doi.org/10.1016/j cedpsych.2013.06.003.

Tze, V. M., Klassen, R. M., \& Daniels, L. M. (2014). Patterns of boredom and its relationship with perceived autonomy support and engagement. Contemporary Educational Psychology, 39, 175-187. http://dx.doi.org/10.1016/j.cedpsych.2014.05. 001

Urdan, T. (2004a). Predictors of academic self-handicapping and achievement: Examining achievement goals, classroom goal structures, and culture. Journal of Educational Psychology, 96, 251-264. http://dx.doi.org/10.1037/0022-0663.96.2.251.

Urdan, T. (2004b). Using multiple methods to assess students' perceptions of classroom goal structures. European Psychologist, 9, 222-231. http://dx.doi.org/10.1027/10169040.9.4.222.

Urdan, T. (2010). The challenges and promise of research on classroom goal structures. In J. L. Meece, \& J. S. Eccles (Eds.). Handbook of research on schools, schooling, and human development (pp. 92-108). New York: Routledge.

Urdan, T., \& Midgley, C. (2001). Academic self-handicapping: What we know, what more there is to learn. Educational Psychology Review, 13, 115-138. http://dx.doi.org/10. 1023/A:1009061303214.

Vansteenkiste, M., Lens, W., Elliot, A. J., Soenens, B., \& Mouratidis, A. (2014). Moving the achievement goal approach one step forward: Toward a systematic examination of the autonomous and controlled reasons underlying achievement goals. Educational Psychologist, 49, 153-174. http://dx.doi.org/10.1080/00461520.2014.928598.

Wolters, C. A. (2004). Advancing achievement goal theory: Using goal structures and goal orientations to predict students' motivation, cognition, and achievement. Journal of Educational Psychology, 96, 236-250. http://dx.doi.org/10.1037/0022-0663.96.2. 236. 